\title{
APLIKASI AKUNTANSI PEMBERIAN KREDIT ANGGOTA PADA KOPERASI PRIMKOPPOL DI POLRES KUNINGAN
}

\author{
Widya Jati Lestari ${ }^{1)}$, Marsani Asfi' ${ }^{2)}$,Widya Lelisa Army ${ }^{3)}$, Dhea Shari Ramadhany ${ }^{4)}$ \\ Universitas Catur Insan Cendekia, Cirebon, Jawa Barat. \\ email: widya.jatilestari@cic.ac.id ${ }^{1)}$, marsani.asfi@cic.ac.id ${ }^{2}$, widyalelisa0495@gmail.com ${ }^{3)}$, \\ dheashari23@gmail.com ${ }^{4)}$, dasrilaldo1994@gmail.com ${ }^{5)}$
}

\begin{abstract}
Abstrak
Koperasi PRIMKOPPOL (Primer Koperasi Kepolisian) Polres Kuningan merupakan salah satu koperasi yang mempunyai andil besar terhadap kesejahteraan anggotanya. Dalam pencatatan pinjaman anggota koperasi PRIMKOPPOL Polres Kuningan pengelolaan data masih menggunakan komputerisasi sederhana, jadi banyak kesalahan dalam mencatat data anggota yang akan meminjam. Maka diperlukan sebuah aplikasi berbasis website yang akan memudahkan pengelolaan data pinjaman anggota di koperasi PRIMKOPPOL Polres Kuningan.Metode penelitian yang digunakan dalam pembuatan aplikasi akuntansi pemberian kredit anggota koperasi PRIMKOPPOL berbasis website ini dengan pengumpulan data observasi, wawancara dan studi kepustakaan yang tiap masing-masing memiliki data sekunder dan data primer didalamnya. Alat pengembangan sistem dengan model proses flowchart, flowmap, diagram konteks, data flow diagram, model data yang digunakan entity relationship diagram, dan rancangan database. Metode bahasa aplikasi pemrograman adalah mengunakan database didalamnya yaitu PHP dan MySQL dan metode perancangan aplikasi perangkat lunak.Aplikasi Akuntansi Pemberian Kredit Anggota pada Koperasi PRIMKOPPOL di Polres Kuningan dapat menghasilkan data kredit anggota, slip pencairan, dan jurnal yang akan memudahkan kegiatan koperasi PRIMKOPPOL Polres Kuningan.
\end{abstract}

Kata Kunci : Aplikasi, Akuntansi, Koperasi, Kredit, Website.

\begin{abstract}
PRIMKOPPOL Cooperative (Primary Police Cooperative) Kuningan Police is one of the cooperatives that has a big share in the welfare of its members. In recording loans for members of the PRIMKOPPOL cooperative, Kuningan Police, data management still uses simple computerization, so there are many mistakes in recording data on members who will borrow. Then a website-based application is needed that will facilitate the management of member loan data in the Kuningan PRIMKOPPOL cooperative. The research method used in making the accounting application for crediting members of the PRIMKOPPOL cooperative is based on this website by collecting observation data, interviews and literature study, each of which has secondary data and primary data therein. System development tools with flowchart process models, flowmaps, context diagrams, data flow diagrams, data models used entity relationship diagrams, and database design. The programming application language method is to use databases in it, namely PHP and MySQL and software application design methods. The Accounting Application for Granting Member Credit at the PRIMKOPPOL Cooperative at the Kuningan Police can produce member credit data, disbursement slips, and journals that will facilitate the activities of the Kuningan Police PRIMKOPPOL cooperative.
\end{abstract}

Keyword: Applications, Accounting, Cooperatives, Credit, Website.

JURSIMA

Jurnal Sistem Informasi dan Manajemen https://ejournal.stmikgici.ac.id/

STMIK GICI 


\section{PENDAHULUAN}

Koperasi merupakan suatu kumpulan dari orang-orang yang mempunyai tujuan atau kepentingan bersama. Jadi koperasi merupakan bentuk dari sekelompok orang yang memiliki tujuan bersama. Pembentukan koperasi berdasarkan atas kekeluargaan dan gotong royong khususnya untuk membantu para anggotanya yang memerlukan bantuan baik berbentuk barang ataupun pinjaman uang.

Koperasi merupakan salah satu bentuk badan usaha yang sesuai dengan kepribadian bangsa Indonesia yang pantas untuk dikembangkan sebagai badan usaha penting dan bukan sebagai alternative terakhir. Karena dalam Undang-Undang Republik Indonesia No 25 tahun 1992 tentang Perkoperasian, menyatakan bahwa koperasi adalah sebagai gerakan ekonomi rakyat maupun sebagai badan usaha berperan untuk mewujudkan masyarakat yang maju, adil dan makmur berlandaskan Pancasila dan Undang-Undang Dasar 1945 dalam tata perekonomian nasional yang disusun sebagai usaha bersama berdasarkan atas kekeluargaan dan demokrasi ekonomi.

Koperasi PRIMKOPPOL (Primer Koperasi Kepolisian) Polres Kuningan merupakan salah satu koperasi yang mempunyai andil besar terhadap kesejahteraan anggotanya. Koperasi ini disamping memasarkan produk barang seperti kebutuhan sehari-hari maupun kebutuhan atribut anggota kepolisian dan juga terdapat jasa pinjaman uang untuk para anggotanya. Simpan pinjam merupakan simpanan yang dikumpulkan bersama dan dipinjamkan kepada anggota yang memerlukan pinjaman dalam berbagai usaha dimana anggota mengajukan permohonan tertulis kepada pengurus dengan

\section{JURSIMA}

Jurnal Sistem Informasi dan Manajemen mencantumkan jumlah uang yang diperlukan, kemudian pengurus mempertimbangkan dan memutuskan permohonan pinjaman sesuai dengan kemampuan koperasi pada saat itu dimana pengurus berhak menentukan besarnya jumlah pinjaman.

Dalam pencatatan pinjaman anggota koperasi PRIMKOPPOL Polres Kuningan pengelolaan data masih menggunakan komputerisasi sederhana, jadi banyak kesalahan dalam mencatat data anggota yang akan meminjam. Dengan adanya perkembangan teknologi dibutuhkan suatu sistem untuk pengolahan data yang dapat mempermudah proses pengolahan data pinjaman para anggota koperasi PRIMKOPPOL Polres Kuningan. Maka diperlukan sebuah aplikasi berbasis website yang akan memudahkan pengelolaan data pinjaman anggota di koperasi PRIMKOPPOL Polres Kuningan.

Berdasarkan uraian latar belakang tersebut dan pentingnya aplikasi berbasis website dalam pengelolahan data kredit anggota maka akan disajikan dalam bentuk laporan tugas akhir dengan judul :

"Aplikasi Akuntansi Pemberian Kredit Anggota pada Koperasi PRIMKOPPOL di Polres Kuningan “

\section{METODE PENELITIAN}

Pengumpulan Data adalah teknik atau cara yang dilakukan oleh peneliti untuk mengumpulkan data. Pengumpulan data dilakukan untuk memperoleh informasi yang dibutuhkan dalam rangka mencapai tujuan penelitian. Pengumpulan data yang penyusun gunakan adalah sebagai berikut :

1. Observasi 
Teknik yang dilakukan adalah dengan cara pengamatan secara langsung yang dilakukakan saat penelitian

a. Data primer: Gambaran umum perusahaan, prosedur yang terkait struktur organisasi, dan tugas masing-masing.

b. Data sekunder: Dokumen-dokumen yang ada di Primkoppol Polres Kuningan seperti permohonan pinjaman uang, sejarah perusahaan, visi misi.

2. Wawancara

a. Data primer: Data hasil analisa wawancara dan data hasil pengamatan secara langsung oleh penyusun.

b. Data sekunder: Laporan hasil analisa wawancara dan dokumendokumen yang terdapat pada saat pengamatan secara langsung.

3. Studi kepustakaan

a. Data primer: Buku, Teksbook dan jurnal.

b. Data sekunder : Artikel ilmiah, Google Scholar dan website

\section{HASIL DAN PEMBAHASAN}

Pada bab ini akan uraikan bagaimana implementasi sistem yang telah dirancang agar dapat digunakan dan dipahami dengan sebaik mungkin. Implementasi sistem meliputi tampilan halaman web,input, output, perangkat lunak serta perangkat keras.

1. Tampilan Menu Halaman Awal

\section{JURSIMA}

Jurnal Sistem Informasi dan Manajemen

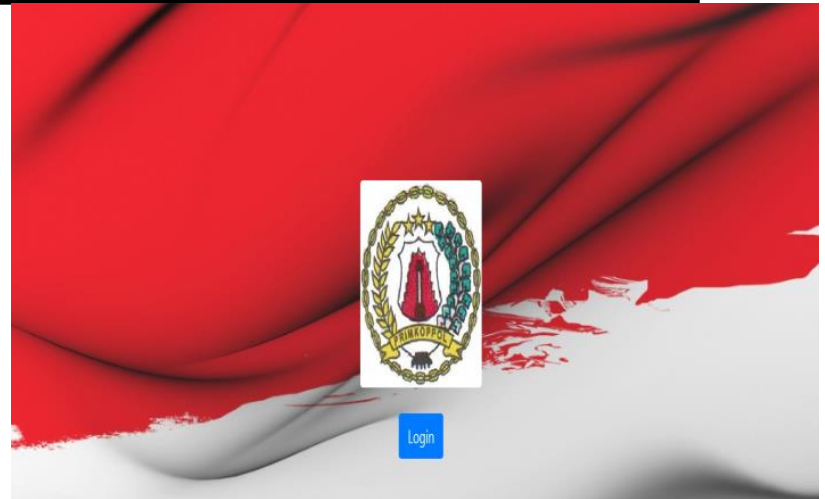

Gambar 3.1 Tampilan Index

Rancangan index adalah rancangan yang merupakan halaman muka ketika aplikasi dijalankan.

\section{Tampilan Form Login}

Form Login merupakan form utama yang digunakan bagian simpan pinjam agar dapat mengakses web aplikasi tersebut sesuai dengan akses yang dimiliki oleh setiap bagian.

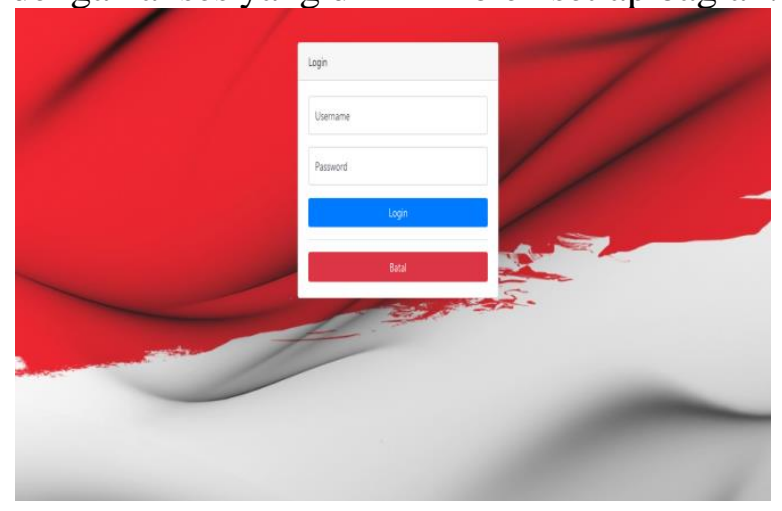

\section{Gambar 3.2 Form Login Bagian Simpan Pinjam}

\section{Form Menu Tampilan Utama Bagian Simpan Pinjam}

https://ejournal.stmikgici.ac.id/ STMIK GICI 


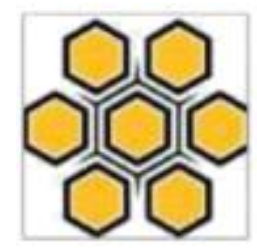

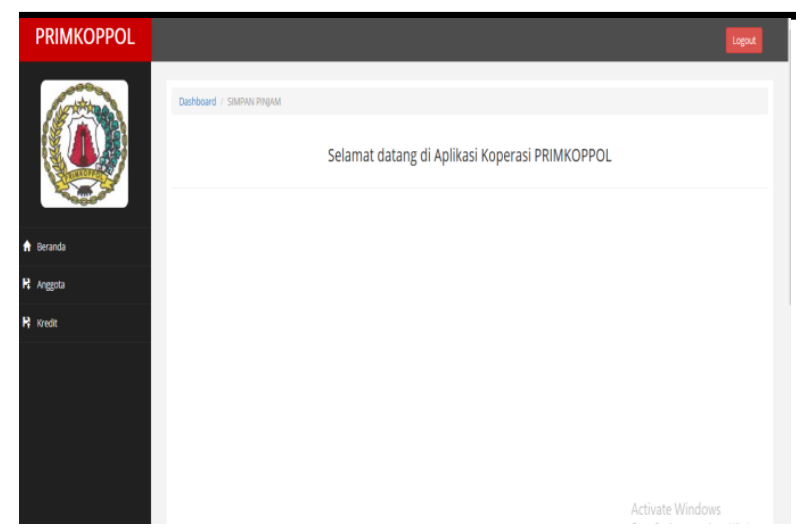

Gambar 3.3 Form Menu Tampilan Utama Bagian Simpan Pinjam

form menu bagian simpan pinjam yaitu form yang digunakan oleh bagian simpan

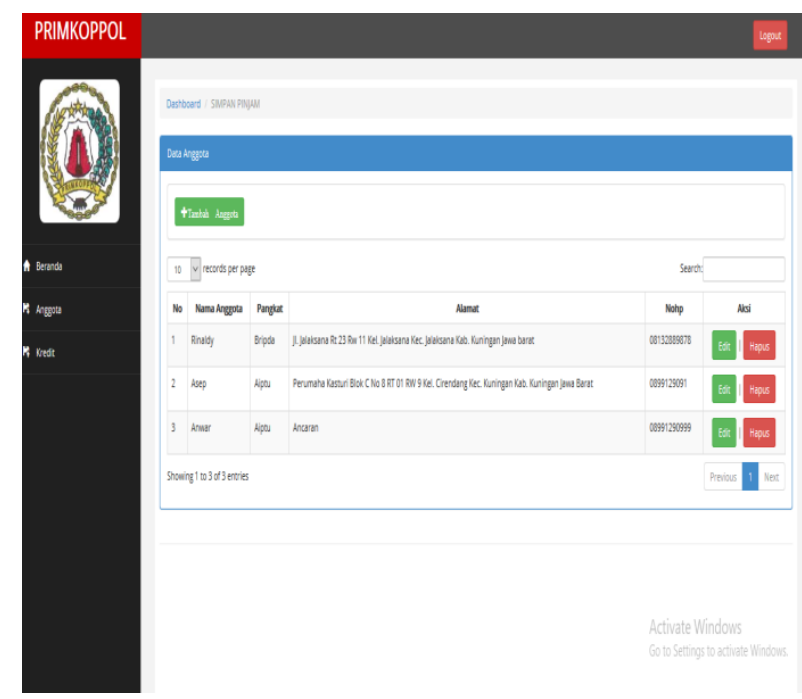

Gambar 3.4 Form Menu Tampilan Anggota

\section{Form Menu Tampilan Tambah Anggota}

Form menu tampilan edit anggota menampilkan tabel edit anggota, di menu ini bagian simpan pinjam dapat merubah data

\section{JURSIMA}

Jurnal Sistem Informasi dan Manajemen pinjam untuk meng-input data anggota, mengedit data anggota, menghapus data anggota, menambahkan data anggota. Selain itu bagian simpan pinjam dapat meng-input data kredit anggota, menghapus data kredit anggota, menambahkan data kredit anggota, dan mencetak laopran kredit anggota.

\section{Form Menu Tampilan Anggota}

Form menu tampilan anggota menampilkan tabel data anggota, di menu ini bagian simpan pinjam dapat melakukan tambah data anggota, edit data anggota, dan hapusdataanggota.

anggota jika terjadi kesalahan pada data anggota.

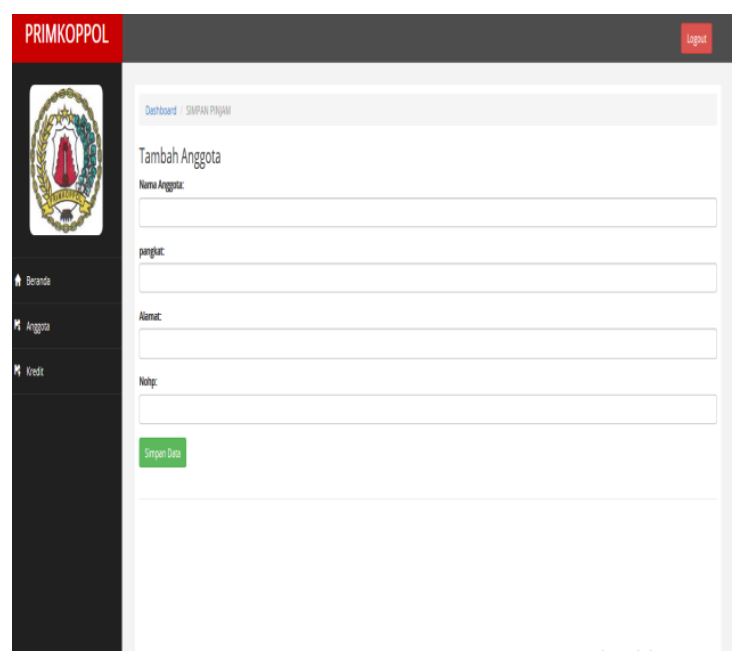

Gambar 3.5 Form Menu Tampilan Tambah Anggota

\section{Form Menu Tampilan Edit Anggota}

Form tampilan tambah anggota menampilkan tabel tambah anggota, di menu ini bagian simpan pinjam dapat meng-input

https://ejournal.stmikgici.ac.id/ STMIK GICI 


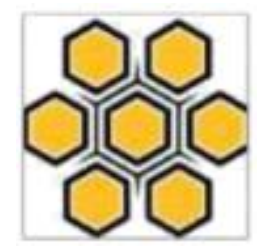

data anggota baru yang ingin melakukan pinjaman pada koperasi PRIMKOPPOL polres Kuningan.

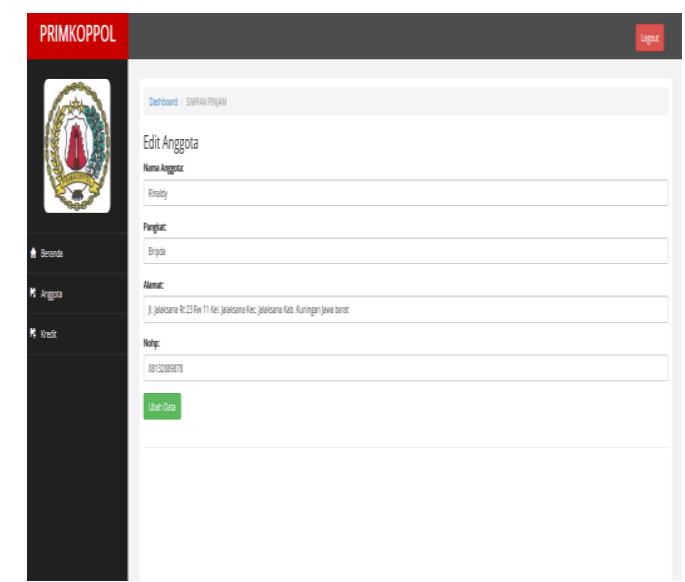

Gambar 3.6 Form Menu Tampilan Edit Anggota

\section{Form Menu Tampilan Kredit}

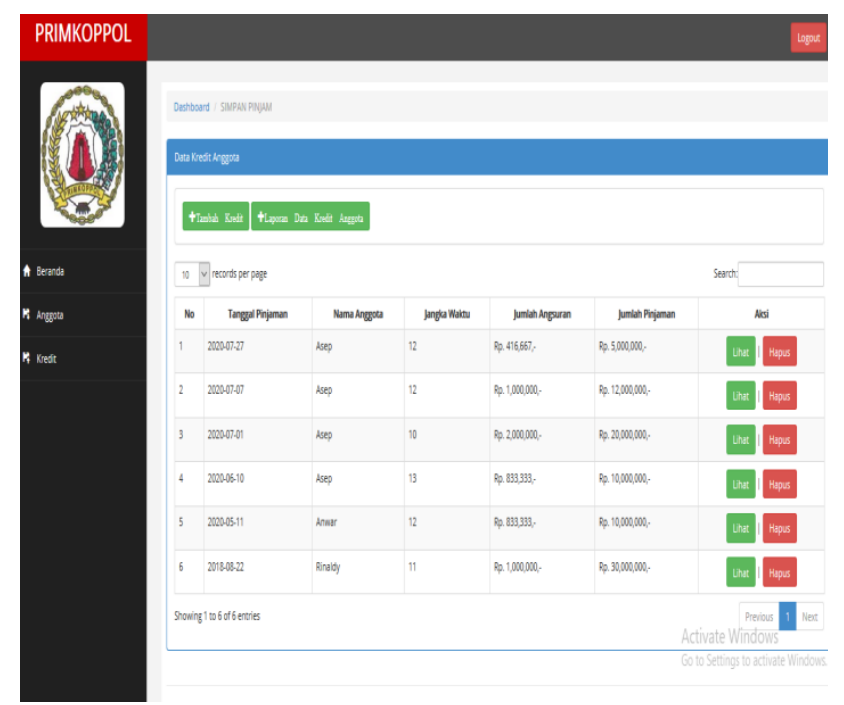

Gambar 3.7 Form Menu Tampilan Kredit

Form menu tampilan kredit menampilkan tabel data kredit anggota, di menu ini bagian simpan pinjam dapat melakukan tambah data kredit anggota, lihat

JURSIMA

Jurnal Sistem Informasi dan Manajemen data kredit anggota, hapus data kredit anggota, dan dapat mencetak laporan data kredit anggota.

\section{Form Menu Tampilan Tambah Kredit}

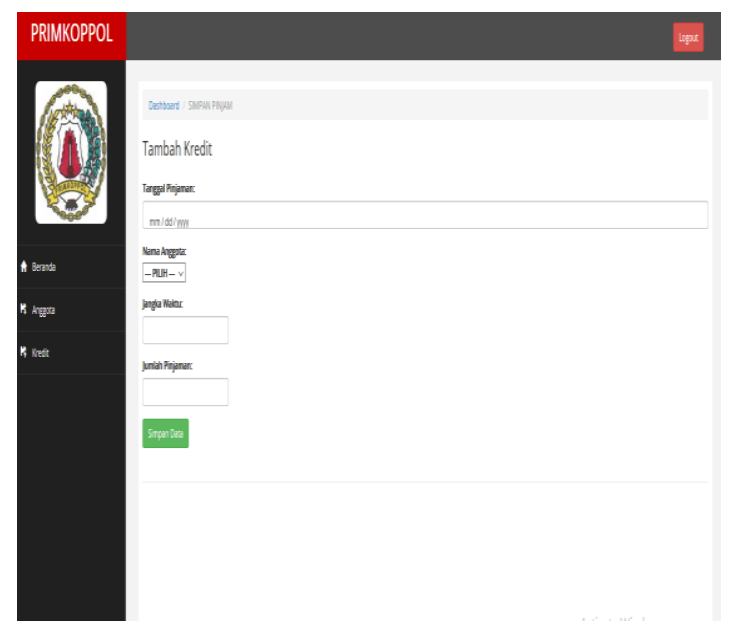

Gambar 3.8 Form Menu Tampilan Tambah Kredit

Form tampilan tambah kredit anggota menampilkan tabel tambah kredit anggota, di menu ini bagian simpan pinjam dapat menginput data kredit anggota yang ingin melakukan pinjaman pada koperasi PRIMKOPPOL polres Kuningan.

\section{Form Menu Tampilan Rincian Kredit}

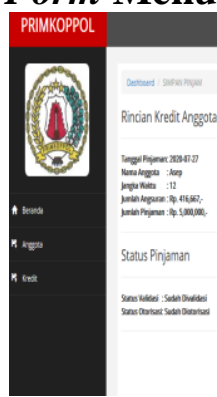

\section{Gambar 3.9 Form Menu Tampilan} Rincian Kredit

Form menu rincian kredit akan menampilkan data rincian kredit anggota, di menu ini bagian simpan pinjam hanya bisa melihat saja.

https://ejournal.stmikgici.ac.id/ STMIK GICI 


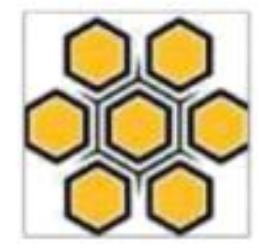

\section{Form Menu Tampilan Laporan Kredit}

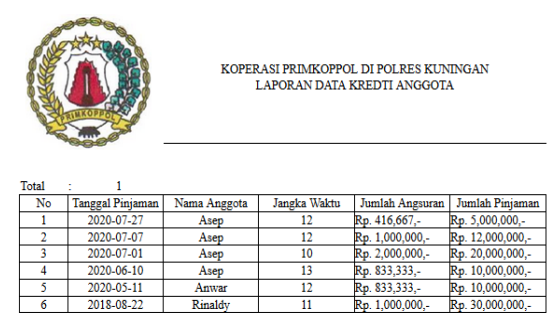

\section{Gambar 3.10 Form Menu Tampilan} Laporan Kredit

Form menu laporan kredit akan menampilkan laporan kredit, di menu ini bagian simpan pinjam melakukan print laporan kredit anggota.

\section{Form Menu Tampilan Utama Bagian Bendahara}

form menu bagian bendahara yaitu form yang digunakan oleh bagian bendahara untuk mevalidasi data kredit anggota, Selain itu bagian bendahara dapat mencetak slip pencairan kredit anggota yang sudah di validasi dan diotorisasi.

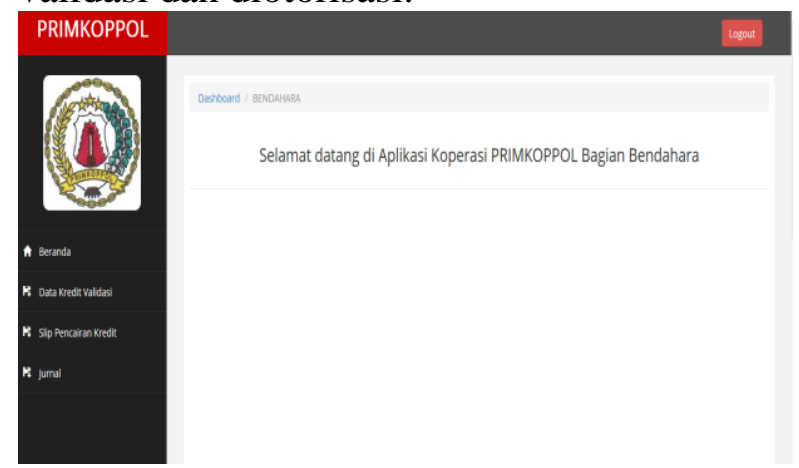

Gambar 3.11 Form Menu Utama Bagian Bendahara

JURSIMA

Jurnal Sistem Informasi dan Manajemen

\section{Form Menu Tampilan Data Kredit Validasi}

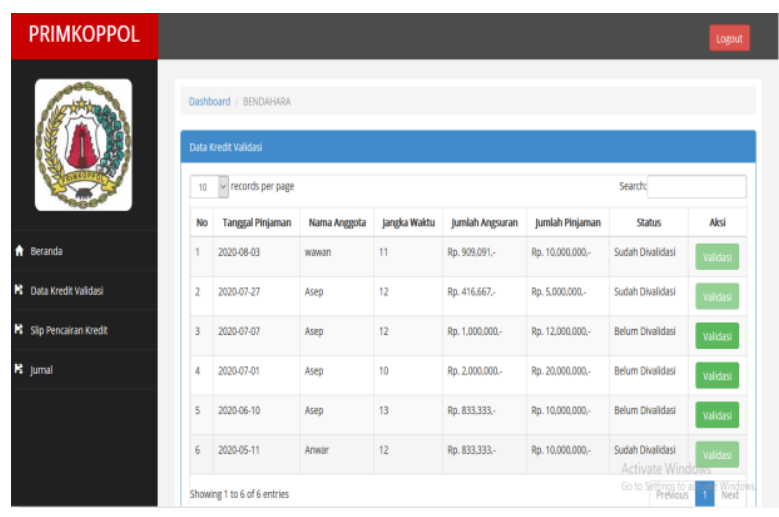

\section{Gambar 3.12 Form Menu Data Kredit} Validasi

Form tampilan data kredit validasi yaitu form yang digunakan oleh bagian bendahara untuk mevalidasi data kredit anggota.

\section{Form Menu Tampilan Validasi}

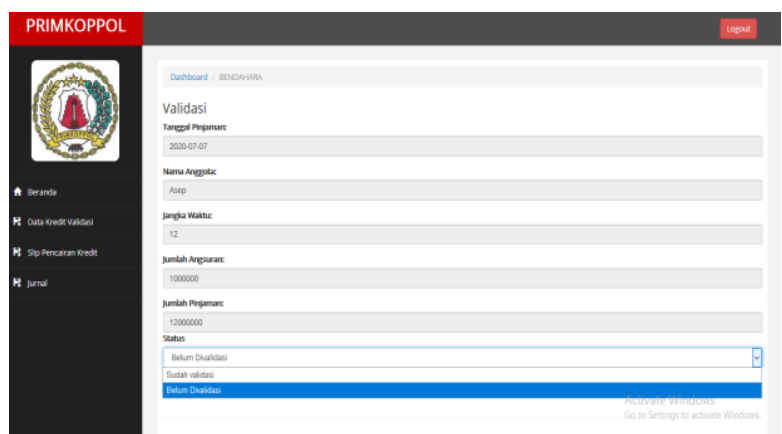

Gambar 3.13 Form Menu Validasi

Form tampilan data kredit validasi yaitu form yang digunakan oleh bagian bendahara untuk mevalidasi data kredit anggota. https://ejournal.stmikgici.ac.id/ STMIK GICI 


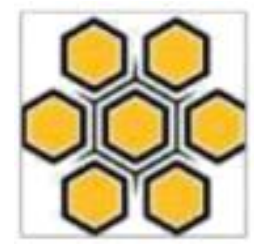

14.Form Menu Tampilan Slip Pencairan Kredit

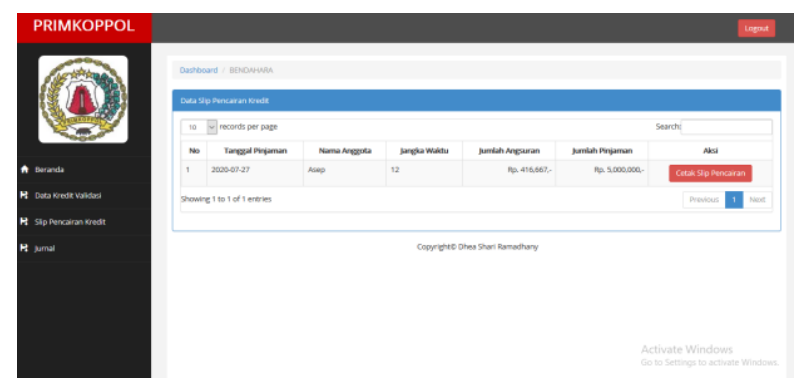

\section{Gambar 3.14 Form Menu Slip Pencairan Kredit}

Form tampilan slip pencairan kredit yaitu form yang digunakan oleh bagian bendahara untuk melihat data yang sudah diotorisasi, setelah itu bagian bendahara dapat mencetak slip pencairan.

\section{Form Menu Tampilan Cetak Slip Pencairan}

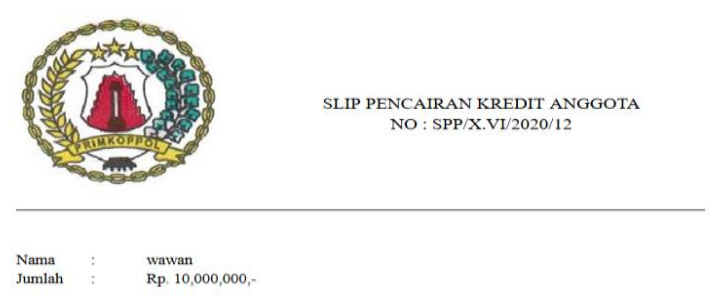

\section{Gambar 3.15 Form Menu Cetak Slip Pencairan Kredit}

Form menu slip pencairan kredit anggota yaitu menampilkan slip pencairan kredit, di menu ini bagian bendahara dapat melakukan print slip pencairan kredit.

\section{JURSIMA}

Jurnal Sistem Informasi dan Manajemen

\section{Form Menu Tampilan Jurnal Umum}

Form menu jurnal umum yaitu menampilkan semua transaksi yang mencakup kredit anggota.

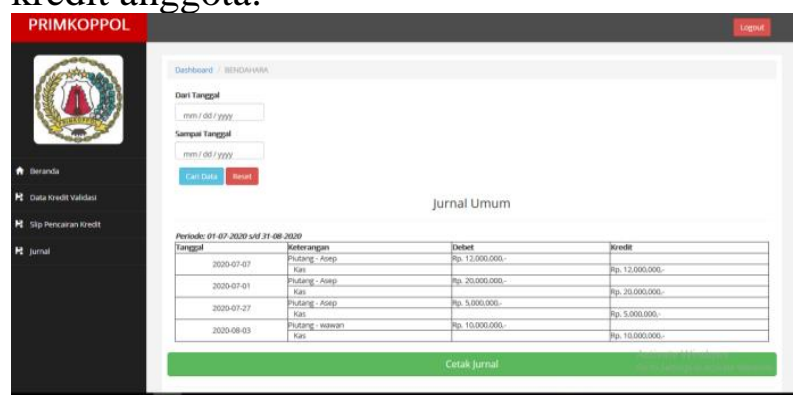

Gambar 3.16 Form Menu Jurnal Umum

\section{Form Menu Cetak Jurnal Umum}

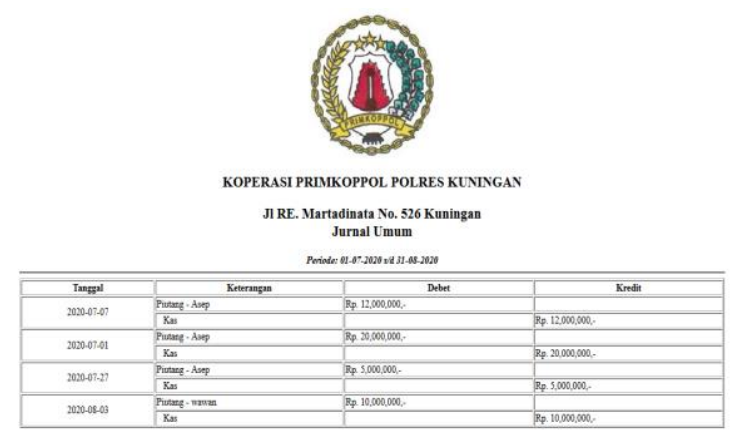

\section{Gambar 3.17 Form Menu Cetak Jurnal Umum}

Form menu cetak jurnal umum yaitu menampilkan keseluruhan laporan jurnal umum, di menu ini bagian bendahara dapat melakukan print jurnal umum.

https://ejournal.stmikgici.ac.id/ STMIK GICI 


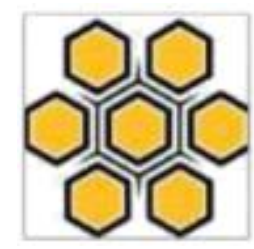

\section{Form Menu Tampilan Utama Bagian Ketua}

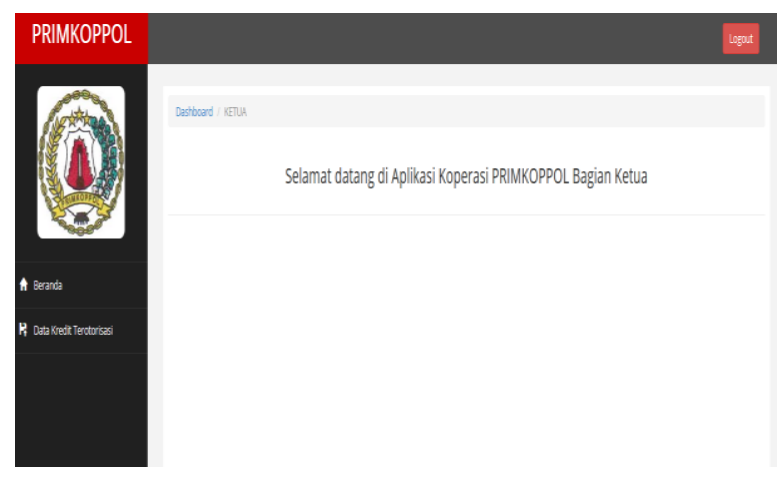

\section{Gambar 3.18 Form Menu Tampilan Bagian Ketua}

form menu bagian ketua yaitu form yang digunakan oleh bagian ketua untuk mengotorisasi data kredit anggota, Selain itu bagian ketua dapat merubah status.

\section{Laporan Data Kredit Anggota}

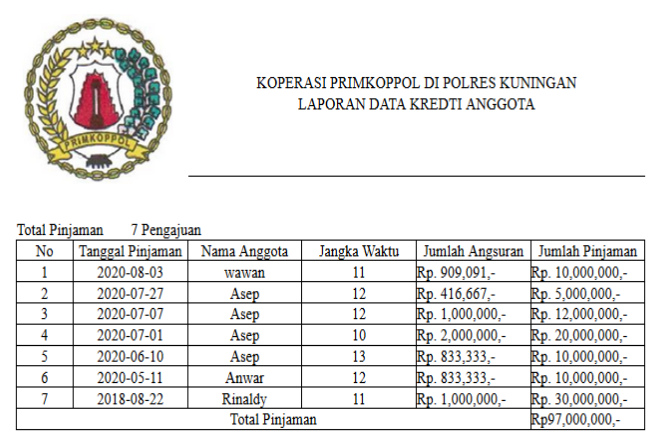

\section{Gambar 3.19 Laporan Data Kredit} Anggota

Laporan kredit anggota akan menampilkan laporan kredit, di menu ini bagian simpan pinjam melakukan print laporan kredit anggota.

\section{Tampilan Cetak Slip Pencairan}

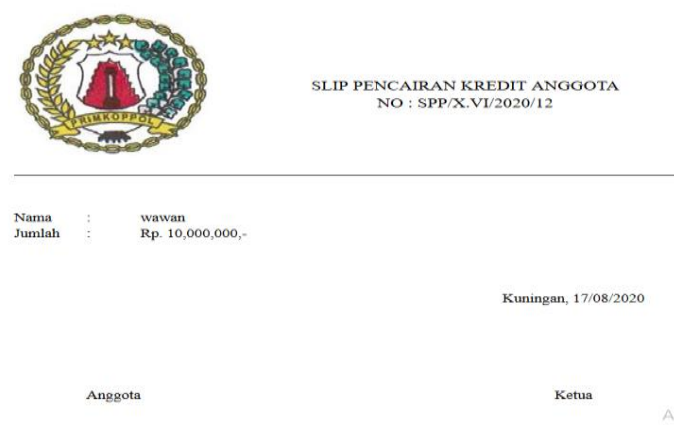

Gambar 3.20 Cetak Slip Pencairan Kredit

Form menu slip pencairan kredit anggota yaitu menampilkan slip pencairan kredit, di menu ini bagian bendahara dapat melakukan print slip pencairan kredit.

\section{Tampilan Cetak Jurnal Umum}

Form menu cetak jurnal umum yaitu menampilkan keseluruhan laporan jurnal umum, di menu ini bagian bendahara dapat melakukan print jurnal umum.

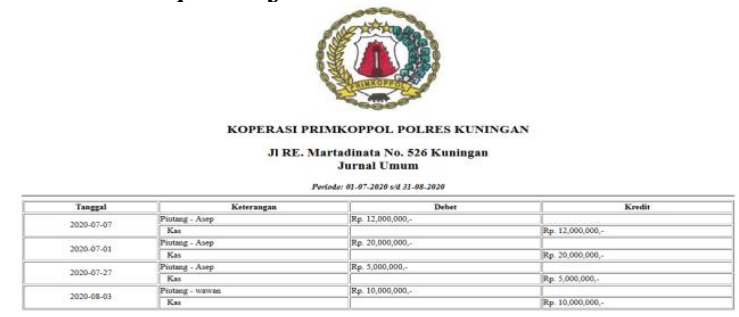

\section{Gambar 4.23 Cetak Jurnal Umum}

JURSIMA

Jurnal Sistem Informasi dan Manajemen https://ejournal.stmikgici.ac.id/ STMIK GICI 


\section{SIMPULAN}

Berdasarkan uraian yang telah dibahas mengenai Aplikasi Akuntansi Pemberian Kredit Anggota pada Koperasi PRIMKOPPOL di Polres Kuningan, maka penyusun membuat kesimpulan bahwa :

Untuk meningkatkan kinerja koperasi PRIMKOPPOL di polres Kuningan, maka dibuatlah Aplikasi Akuntansi Pemberian Kredit Anggota pada Koperasi PRIMKOPPOL di Polres Kuningan. Dengan Bahasa pemrograman dan MYSQL sebagai database koperasi

Sistem yang dirancang ini mampu meminimalkan kesalahan dalam pengolahan data koperasi PRIMKOPPOL di Polres Kuningan. Yang dimana pengolahan datanya menjadi terkomputerisasi.

Pengendalian internal pada program Aplikasi Akuntansi Pemberian Kredit Angoota pada Koperasi PRIMKOPPOL ini adalah bagian simpan pinjam meng-input data kredit, lalu bagian bendahara memvalidasi kredit setelah itu data validasi kredit akan dikirim kebagian ketua, kemudain ketua akan mengotorisasi data kredit yang akan dikirim kembali kebagian bendahara untuk dibuatkan jurnal dan mencetak slip pencairan kredit.

Saran-saran berikut penyusun uraikan untuk bisa melanjutkan penelitian ini antara lain:

1. Apabila aplikasi ini diterapkan perlu ditingkatkan sampai ke bagian pembukuan dan laporan keuangan.

2. Dalam aplikasi ini belum menghasilkan kartu anggota, pembagian SHU.

3. Apabila aplikasi ini diterapkan maka perlu ditingkatkan dibagian unit

JURSIMA

Jurnal Sistem Informasi dan Manajemen simpan pinjam untuk menambahkan simpanan wajib, pokok dan simpanan sukarela.

\section{UCAPAN TERIMA KASIH}

Penulis sampaikan ucapan terima kasih kepada semua pihak yang terlibat sehingga penelitian ini bisa berjalan dengan lancar, baik dan sesuai dengan yang diharapkan.

\section{DAFTAR PUSTAKA}

Arzino. 2013. Sistem Informasi Koperasi Simpan Pinjam Berbasis Web. Skripsi Universitas Pembangunan Nasional "Veteran" 2013. Jawa Timur.

Betha. 2017. Pemrograman Web Dengan Web PHP 7.Bandung: Informatika Bandung.

Kasmir. 2016. Analisis Laporan Keuangan. Jakarta: Raja Grafindo Persada.

Mulyadi. Sistem Akuntansi, Edisi 4, 2016, Jakarta:Salemba Empat.

Pranama. 2013. Aplikasi Koperasi Simpan

Pinjam Menggunakan Metode

Berorientasi Objek. Tugas Akhir

Universitan Bina Darma 2013. Palembang

Pratama Ari. 2015. Sistem Informasi Simpan Pinjam Berbasis Web Pada Koperasi Pegawai Republik Indonesia. Skripsi Sekolah Tinggi Manajemen Informatika 2015. Palembang.

Puspitasari Fina. 2018. Rancang Bangun Aplikasi Simpan Pinjam Pada Koperasi Sumber Rezeki. Tugas Akhir Stikom Fakultas Teknologi Dan Informatika 2018. Surabaya.

https://ejournal.stmikgici.ac.id/ STMIK GICI 
Revrisond Baswir. 2013. Koperasi Indonesia, Edisi Kedua. Yogyakarta: Graha Ilmu.

Simanjuntak Wanti. 2017. Perancangan Sistem Informasi Simpan Pinjam Pada Koperasi Karyawan Jujur Makmur. Skripsi Sekolah Tinggi Manajemen Informatika Dan Komputer 2017. Batam.
Wahyuni Endah. 2019. Prosedur Simpan Pinjam Pada PRIMKOPPOL Polres Purworejo. Laporan Magang Universitast Islam Indonesia 2019. Yogyakarta.

Yepi.2005.Analisis Sistem Informasi Akuntansi Pemberian Kredit.Skripsi Universitas Sebelas Maret Surakarta 2005.Surakarta. 